\title{
Karakterisasi Fisis Hubungan Densitas, Resistivitas, Kecepatan (Vp), dan Atenuasi pada Batuan Vulkanik (Studi Kasus Gunung Arjuno- Welirang, Jawa Timur)
}

\author{
Yulia Nur Fajrina, Wien Lestari, Firman Syaifuddin \\ Jurusan Teknik Geofisika, Fakultas Teknik Sipil dan Perencanaan, Institut Teknologi Sepuluh \\ Nopember (ITS) \\ J1. Arief Rahman Hakim, Surabaya 60111 Indonesia \\ e-mail: wien@geofisika.its.ac.id
}

\begin{abstract}
Abstrak - Sebuah kawasan yang memiliki aktivitas vulkanik, mempunyai potensi SDA yang dapat dimanfaatkan sebagai sumber energi panas bumi hingga cadangan hidrokarbon. Tujuan dari penelitian ini ialah untuk mengkarakterisasi fisis dan analisa hubungan antara parameter densitas, kecepatan Vp, atenuasi, dan resistivitas pada batuan vulkanik studi kasus Gunung Arjuno-Welirang. Penelitian diawali dengan pengambilan sampel di lapangan dan pembuatan coring batuan sehingga didapatkan 45 coring batuan, dari 16 sampel batuan, yang mewakili 6 satuan batuan, kemudian dilakukan pengukuran parameter resistivitas dengan metode konfigurasi axial resistivity, pengukuran densitas dengan prinsip Archimedes, dan pengukuran kecepatan Vp serta atenuasi dengan transmisi gelombang ultrasonik. Maka didapatkan hasil rentang parameter densitas batuan vulkanik Arjuno Welirang berkisar antar $2400-2900 \mathrm{~kg} / \mathrm{m}^{3}$, sedangkan rentang resistivitas bervariasi dari $30-185 \mathrm{kOhm} . \mathrm{m}$, kemudian rentang nilai kecepatan Vp bervariasi dari 5100-6700 m/s, dengan koefisien atenuasinya memiliki rentang $0.05-0.23 \times 10^{-3} \mathrm{~dB} / \mathrm{m}$, dimana nilai densitas akan berbanding lurus dengan kecepatan $\mathrm{Vp}$, dan nilai resistivitas akan berbanding terbalik dengan densitas-kecepatan Vp. Berdasarkan analisa petrologi batuan vulkanik ArjunoWelirang memiliki tipe intermediate-mafik dengan nama batuan dominasi andesit-basaltik dan basalt.
\end{abstract}

Kata kunci-Atenuasi, Batuan Vulkanik, Densitas, Kecepatan Vp, Resistivitas

\section{PENDAHULUAN}

$\mathrm{D}$ I Indonesia, sebaran gunung aktif dibagi menjadi empat busur gunung api, yakni Busur Gunung Api Sunda, Busur Gunung Api Banda, Busur Gunung Api Halmahera, dan Busur Gunung Api Sulawesi Utara-Kepulauan Sangihe[1]. Sebuah kawasan yang memiliki aktivitas vulkanik, mempunyai potensi sumber daya alam yang dapat dimanfaatkan sebagai sumber energi panas bumi hingga cadangan hidrokarbon. Sampai saat ini karakterisasi fisis yang berhasil dilakukan oleh metode geofisika untuk lingkungan vulkanik hanya metode gravity, geolistrik, magnetik dan elektromagnetik. Sedangkan metode sesimik yang memanfaatkan kecepatan gelombang belum mendapatkan hasil eksplorasi yang baik. Tujuan dari penelitian ini ialah untuk mengkarakterisasi fisis dan analisa hubungan antara parameter densitas, kecepatan $\mathrm{Vp}$, atenuasi, dan resistivitas pada batuan vulkanik studi kasus Gunung Arjuno-Welirang, serta menganalisa petrologi batuan vulkanik.

\section{A. Geologi Regional}

Gunung Arjuno - Welirang secara administrasi terdapat di 3 wilayah kabupaten, Kabupaten Malang, Mojokerto, dan Pasuruan dengan letak geografis pucak terdapat pada $7^{\circ} 40^{\prime}$ $7^{\circ} 53^{\prime} \mathrm{LS} 112^{\circ} 31^{\prime} 7^{\prime \prime}$ - $112^{\circ} 42^{\prime} 52^{\prime \prime}$ Kedua gunung api ini merupakan tipe Gunungapi Strato tipe A. Batuan penyusun kompleks gunung tersebut ialah andesit-basaltik, yang dihasilkan oleh tiga buah erupsi pusat dari G. Arjuno Tua, G. Arjuno Muda dan G. Welirang berupa aliran lava, aliran piroklastik, jatuhan piroklastik dan lahar yang sebarannya ke arah utara dan barat[2] (Gambar 1).

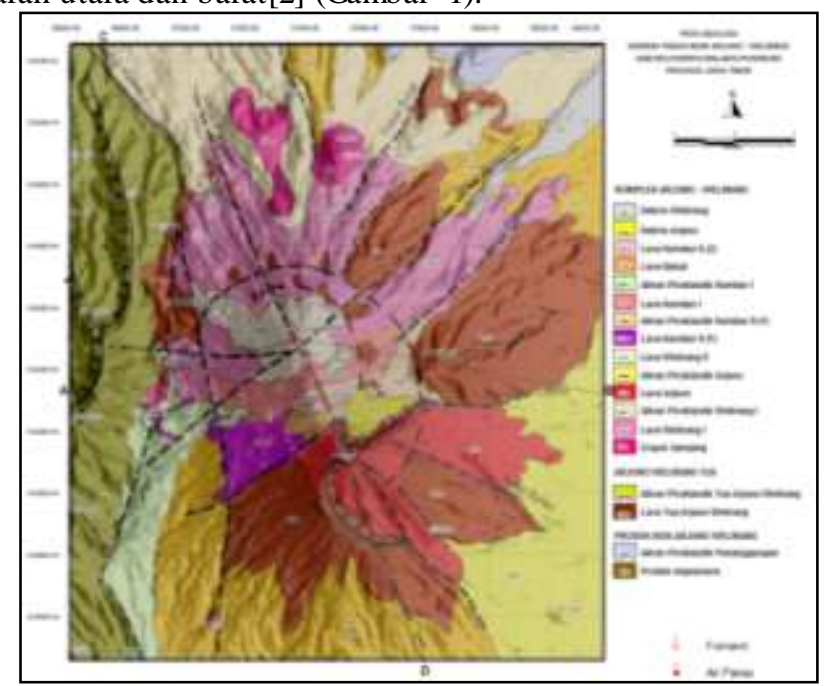

Gambar. 1. Komponen Satuan Batuan dan Struktur Geologi Komplek Gunung Arjuno-Welirang

\section{B. Karakter Fisik Batuan}

1) Densitas Batuan Vulkanik

Untuk mengetahui densitas bulk ada beberapa faktor yang mempengaruhi nilainya diantaranya komposisi mineral (densitas mineral dan fraksi volume); porositas (pori dan fracture) dan porositas fluida pori batuan[3]. Untuk mendapatkan nilai densitas bulk batuan digunakan persamaan dibawah ini:

$$
\rho=\sum_{\mathrm{i}=1}^{\mathrm{n}} \rho_{i} \cdot V_{i}
$$


dimana :

$$
\begin{aligned}
& \rho_{i}=\text { densitas mineral-mineral, densitas fluida } \\
& V_{i}=\text { fraksi volume }
\end{aligned}
$$

Densitas batuan beku sangat dipengaruhi oleh kandungan pH mineralnya (felsik - mafik). Rentang nilai densitas antar batuan beku cenderung kecil jika dibandingkan batuan sedimen (pengaruh volume fracture), namun nilainya lebih tinggi dibanding batuan sedimen.

2) Kecepatan Vp Batuan Vulkanik

Velocity Vp ialah kecepatan gelombang kompres ional yang mampu ditempuh suatu batuan. Kecepatan Vp memiliki hubungan persamaan yang berbanding lurus dengan densitas. Persamaan umum densitas-kecepatan batuan beku yang sering digunakan diantaranya menggunakan persamaan Christensen \& mooney (1995) [4]dan Godfrey (1997)[5], dimana :

$$
\begin{aligned}
& \rho \text { Christensen }\left(\left(\frac{g}{c m^{3}}\right)=0.541+0.36 V_{p}\right. \\
& \rho \text { Godfrey }\left(\frac{g}{c^{3}}\right)=2.4372+0.076 V_{p}
\end{aligned}
$$

dimana :

$$
\begin{array}{ll}
\rho & =\text { Densitas } \\
V p & =\text { Kecepatan Vp }
\end{array}
$$

3) AtenuasiGelombang Seismik Batuan Vulkanik

Atenuasi ialah gabungan antara pelepasan energi dan penyerapan frekuensi medium. Pengaruh atenuasi pada gelombang seismik yakni dengan penurunan amplitudo dan melebarnya sinyal (panjang gelombang). Koefisien atenuasi batuan beku lebih kecil dibanding batuan lainnya (high attenuation). Koefisien atenuasi dan faktor dispasi, dirumuskan dengan :

$$
\propto=\frac{1}{x_{2}-x_{1}} \cdot 20 \cdot \log \left(\frac{A\left(x_{1}\right)}{A\left(x_{2}\right)}\right)
$$

dimana :

$$
\begin{aligned}
& \left.\propto \quad=\text { koefisien atenuasi (dalam } \mathrm{dB} \mathrm{m}^{-1}\right) \\
& A\left(x_{1}\right)=\text { amplitudo pada jarak } \mathrm{x}_{1} \\
& A\left(x_{2}\right)=\text { amplitudo pada jarak } \mathrm{x}_{2} \\
& \mathrm{x}_{1}, \mathrm{x}_{2}=\text { jarak }(\mathrm{m})
\end{aligned}
$$

4) Resistivitas Batuan Vulkanik

Aliran arus listrik di dalam batuan dipengaruhi oleh banyaknya elektron bebas. Faktor yang mempengaruhi nilai resistivitas batuan : kandungan air, tekstur batuan, jenis batuan, porositas dan permeabilitas, mineral lempung, salinitas [3].

\section{METODOLOGI PENELITIAN}

\section{A. Tahapan Penelitian}

Tahapan metodologi pada penelitian ini dimulai dengan studi literatur dan tinjauan geologi untuk mempelajari karakter fisis batuan vulkanik, parameternya, serta kondisi geologi lapangan penelitian. Kemudian dilakukan pengambilan sampel dilapangan berupa blok batuan dan hand sampling, serta proses coring. Dari coring yang didapat, dilakukan berbagi pengukuran parameter fisis batuan dan pendeskripsian petrologi, serta dianalis a hubungan antara parameter fisis dan pengaruh petrologi batuan terhadap parameter fis is.

\section{B. Data Penelitian}

Pada pengambilan sampel di lapangan dan pembuatan coring batuan sehingga didapatkan 45 coring batuan, dari 16 sampel batuan, yang mewakili 6 satuan batuan (Gambar 3). Enam satuan batuan tersebut, yakni Lava Anjansmara (Qla), Lava Tua Arjuno Welirang (Qltaw), Aliran Piroklastik Tua Arjuno Welirang (Qaptaw), Lava Erupsi Samping (Qes) Lava Welirang I (Qlw I), Aliran Piroklastik Welirang (Qapw).

\section{Metode Penelitian}

Pengukuran densitas sampel coring batuan dilakukan dengan menggunakan prinsip Archimedes. Untuk melakukan pengukuran densitas dilakukan dengan mengambil data variabel ukur massa kering (Mk), berat kering (Wk), berat basah atau berat batuan saat batuan tersaturasi air dan dibuat dalam keadaan melayang (Wsat).

Pengukuran data resistivitas dilakukan dengan menggunakan alat ukur resistivitymeter yang terhubung dengan elektroda pada batuan. Elektroda dibuat dari lempengan tembaga yang menyentuh langsung ke batuan, dimampatkan, dan dihubungkan ke resistivitymeter[6] (Gambar 2a). Variabel yang terukur pada resistivity meter ini berupa arus injeksi yang mengalir masuk ke batuan(Ampere) dan beda potensial di kedua ujung batuan (Volt)

Pengukuran parameter $\mathrm{Vp}$ dan atenuasi menggunakan perangkat signal generator, tranducer, receiver, dan osiloskop (Gambar 2b). Kemudian variabel yang diukur pada pengambilan data kecepatan $\mathrm{Vp}$ ialah waktu tempuh gelombang longitudinal dan dimensi panjang batuan. Pengukuran atenuasi dapat dilakukan dengan mengukur peak to peak amplitude pada suatu batuan dengan dimensi panjang $\mathrm{x}$ dan membandingkannya dengan variasi dimensi panjang yang berbeda, namun jenis batuan yang sama.
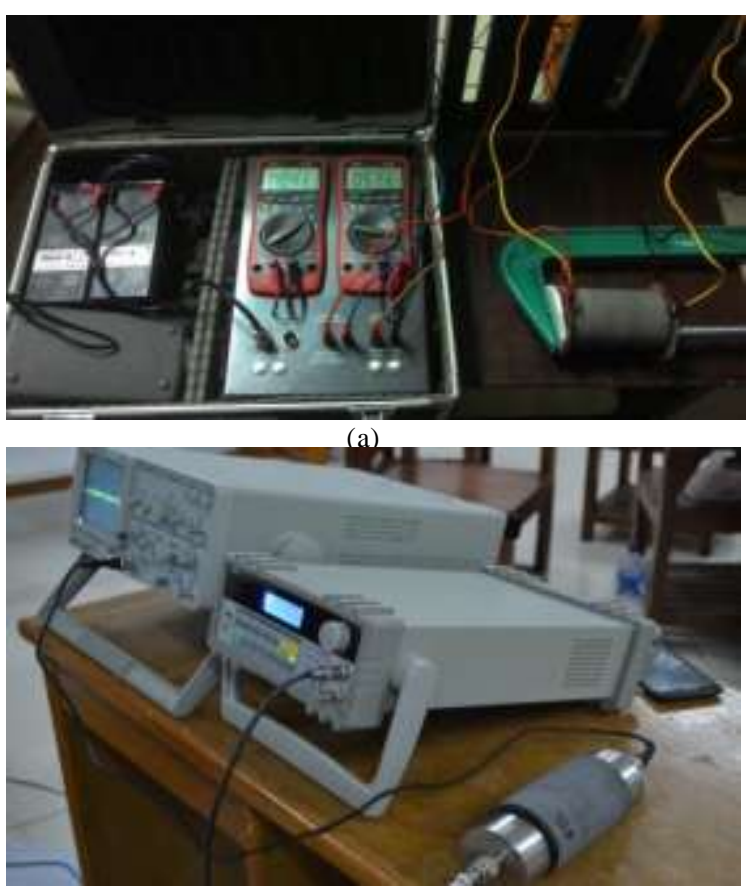

(b)

Gambar. 2. Metode pengukuran Resistivitas (a)dan Pengukuran Kecepatan Vp dan atenuasi pada batuan 


\section{HASIL DAN ANALISA}

\section{A. Analisa Petrologi Batuan Vulkanik}

Berdasarkan analisa petrologi yang dilakukan pada sampel (Gambar 3), batuan vulkanik Arjuno-Welirang memiliki tipe intermediate-mafik dengan nama batuan dominasi andesitbasaltik dan basalt. Disebut tipe intermediate hingga mafik, dikarenakan komposisi mineralnya sebagian besar sama seperti, kuarsa, plagioklas, piroksen, olivin dan amfibol. Yang membedakan antar satuan batuan satu dengan satuan batuan lainnya hanya struktur dan persantase komposisi dominan mineral.
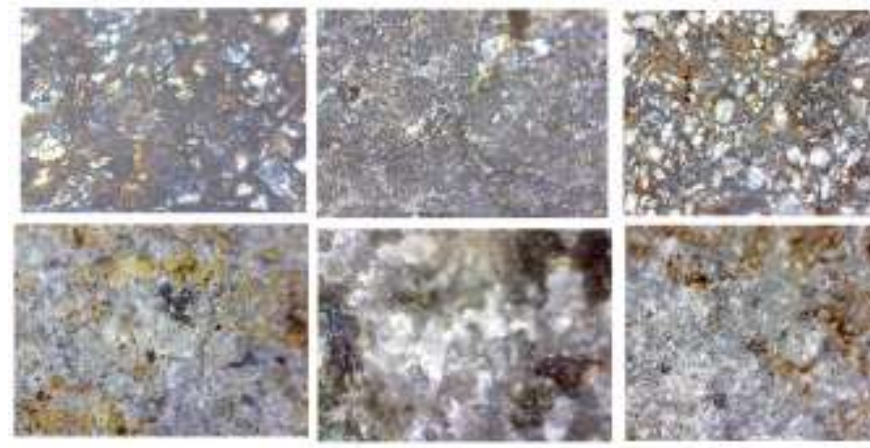

Gambar. 3. Hand sampling section pada 6 satuan batuan dengan pembesaran $100 \mathrm{x}$

\section{B. Analisa Hubungan Parameter Fisis Batuan Vulkanik}

Berdasarkan perbedaan trend dan sebaran data pada crossplot, maka batuan vulkanik sampel dapat dikelompokkan 3 kategori produk batuan vulkanik, yakni produk kategori lava, piroklastik, dan lava vesikular.

Berdasarkan hasil penelitian rentang parameter densitas batuan vulkanik Arjuno Welirang berkisar antar $2400-2900$ $\mathrm{kg} / \mathrm{m} 3$, sedangkan rentang resistivitas bervariasi dari 30-185 kOhm.m, kemudian rentang nilai kecepatan Vp bervariasi dari 5100-6700 m/s, dengan koefisien atenuasinya memiliki rentang $\quad 0.05-0.23 \times 10-3 \mathrm{~dB} / \mathrm{m}$. Dimana persamaan hubungan antar parameternya di jelaskan pada Tabel 1.

Tabel 1 .

Hubungan parameter fisis batuan vulkanik kondisi dry rock

\begin{tabular}{|c|c|c|}
\hline Hubungan Parameter & Persamaan & Keterangan \\
\hline Densitas - Kecepatan Vp & $\mathrm{Vp}=2.7778 \rho-1.5$ & $\begin{array}{c}\text { Berbanding } \\
\text { lurus }\end{array}$ \\
\hline Resistivitas-Kecepatan Vp & $\mathrm{Vp}=13328 \rho^{-0.0 / 0}$ & $\begin{array}{c}\text { Berbanding } \\
\text { terbalik }\end{array}$ \\
\hline Densitas - Resistivitas & $\begin{array}{c}\text { presist }=191.94 \mathrm{x}^{3}- \\
1370.9 \mathrm{x}^{2}+3070.2 \mathrm{x}- \\
1988.1(\mathrm{x}=\text { densitas })\end{array}$ & $\begin{array}{l}\text { Berbanding } \\
\text { terbalik }\end{array}$ \\
\hline $\begin{array}{c}\text { Densitas }- \text { Koefisien } \\
\text { Atenuasi }\end{array}$ & $\begin{array}{c}\alpha=0.2747 \rho 2-1.475 \rho+ \\
2.0928\end{array}$ & $\begin{array}{c}\text { Berbanding } \\
\text { terbalik }\end{array}$ \\
\hline $\begin{array}{c}\text { Kecepatan Vp-Koefisien } \\
\text { Atenuasi }\end{array}$ & $\begin{array}{c}\alpha=0.0266 \mathrm{Vp} 2- \\
0.3093 \mathrm{Vp}+1.0184\end{array}$ & $\begin{array}{c}\text { Berbanding } \\
\text { terbalik }\end{array}$ \\
\hline $\begin{array}{c}\text { Resistivitas }- \text { Koefisien } \\
\text { Atenuasi }\end{array}$ & $\begin{array}{c}\alpha=0.2747 \rho^{2}-1.475 \rho+ \\
2.0928\end{array}$ & $\begin{array}{c}\text { Berbanding } \\
\text { lurus }\end{array}$ \\
\hline
\end{tabular}

*Keterangan - Hubungan antar parameter fisis
Sehingga dapat digaris bawahi bahwa pada batuan vulkanik dengan kondisi dry, kecepatan Vp akan berbanding lurus dengan densitas, atau dapat didefinisikan kecepatan Vp akan naik seiring dengan naiknya densitas. Sedangkan resistivitas akan berbading terbalik dengan densitas-kecepatan Vp, atau dapat didefinisikan resistivitas akan semakin naik nilainya, apabila nilai densitas-kecepatan Vp semakin turun nilainya (Gambar 4). Hal ini karena pada kondisi dry rock atau pada saat batuan kering resistivitas batuan yang memiliki pori dengan densitas menurun, lebih akan memiliki nilai resistivitas yang tinggi akibat perantara antar kontak mineralnya tidak serapat dengan kontak mineral pada batuan vulkanik produk lava, sehingga batuan ini tidak konduktif dibandingkan batuan dengan densitas yag lebih besar.

\section{KESIMPULAN}

Dari Penelitian yang sudah dilakukan dapat diambill kesimpulan bahwa :

1. Rentang parameter batuan vulkanik dry rocks memiliki nilai densitas, kecepatan $\mathrm{Vp}$, faktor atenuasi, dan resistivitas yang tinggi dibandingkan dengan batuan kelompok lain seperti batuan sedimen.

2. Dari hasil pengukuran dan analisa pada batuan vulkanik dry rocks, nilai densitas akan berbanding lurus dengan kecepatan Vp, dan nilai resistivitas akan berbanding terbalik dengan densitas-kecepatan Vp.

3. Tipe batuan vulkanik Gunung Arjuno-Welirang merupakan tipe intermediate hingga mafik, dengan dominasi batuan andesit-basaltik dan basalt.

4. Karena hasil parameter fisis (densitas, Vp, atenuasi, dan resistivitas) batuan vulkanik sangat dipengaruhi oleh faktor mineral, tekstur dan struktur batuannya, maka deskirpsi petrologi dapat membantu proses interpretasi hasil pengukuran dan analisa setiap parameter.

\section{DAFTAR PUSTAKA}

[1] Sutikno, Bronto. 2002. Volkanologi. Staf Pengajar pada Jurusan Teknik Geologi Sekolah Tinggi Teknologi Nasional Yogyakarta

[2] Berita Berkala Vulkanologi, Edisi Khusus, 1992, G. Arjuno-Welirang.

[3] Schoen, J. H., 2011, Handbook of Petroleum Exploration and P roduction Volume 8 :Physical Properties of Rocks, Oxford UK, Elsevier.

[4] Christensen, N.I. and Mooney, W.D., 1995. Seismic velocity structure and composition of the continental crust: a global view. J. Geophys. Res., 100, 9761-9788.

[5] Mavko, G., Mukerji T.,Dvorkin J., 2009, The Rock Physics Handbook : Tools for Seismic Analysis of Porous Media, Cambridge University Press, New York

[6] bousrafa, E.M., Somerville, J.M., Hamilton, S.A. Holden, P.W., 2013, A laboratory measurement technique for axial and radial resistivity at ambient or reservoir stress state conditions Institute of PetroleumEngineering, Heriot-WattUniversity, Edinburgh E ,UK 